\title{
Green Synthesis of Silver Nanoparticles by Sargassum Cinctum J. Agardh and their Potential for Seed Germination
}

\author{
Suparna Roy \\ Centre of Advanced Study in Marine Biology, \\ Faculty of Marine Sciences, Annamalai University, \\ Annamalai Nagar, Tamilnadu, India
}

\author{
P. Anantharaman \\ Centre of Advanced Study in Marine Biology, \\ Faculty of Marine Sciences, Annamalai University, \\ Annamalai Nagar, Tamilnadu, India
}

\section{ABSTRACT}

Nanoparticles are recognizing for their applications in various fields of medical sciences and they are also under safety concern. The effects of metals nanoparticles on environment is not yet completely known to us, but some of the study had been elaborated the toxic effects of metal nanoparticles to the environment both aquatic and terrestrial as well as human healths. So, eco-friendly green synthesized nanoparticles are now leading our interest for biosafety purpose. The aqueous solution of brown seaweed (Sargassum cinctum) had been utilized for green synthesized of Silver nanoparticles. The silver nanoparticles were formed due to the reduction of silver nitrate to aqueous silver ions in the presence of seaweed extract. The synthesized silver nanoparticles were characterized using UV-Visible Spectrophotometer, FTIR and Scanning Electron Microscopy. The biochemical compositions such as carbohydrates, proteins, lipids and starch were estimated for the mentioned species according to standard methods and the total phenol, in-vitro antioxidant activity and free radicals DPPH scavenging activities were also estimated. The phytotoxicity of green synthesized silver nanoparticles was evaluated by studying its effect on seed germination of Abelmoschus esculentus, one of the important vegetable items in Indian market.

Keywords: Green synthesis, silver nanoparicles, seed germination

\section{INTRODUCTION:}

Seaweeds are most promising nutritive lower group of plants with thallus structure. They are the incredible renewable marine resources. Some of the seaweeds have been reported for having high carbohydrates, protein, lipids, vitamins and minerals (Rupérez 2002; McDermid and Stuercke 2003; Ortiz et al. 2006; Marsham et al. 2007; Chakraborty and Santra 2008; Matanjun et al. 2009, Manivannan et al. 2008 \& 2009 and Roy et al. 2017a \& b). It is believed that nanoparticles are the agglomerates of nano sized (1$100 \mathrm{~nm}$ ) particles and primarily classified as organic (carbon nanoparticles) and inorganic (magnetic nanoparticles, noble metals nanoparticles such as silver, gold and platinum and semiconductor nanoparticles (zinc oxide \& sulphide, titanium dioxide) (Williams 2008). The nanoparticles had been exposing rapidly into the environment from natural and anthropogenic activities (Klaine et al. 2008 \& Farre et al. 2009), as $15 \%$ of all product in global market (e.g. electronics, engineering, medicine, wound dressing, socks and other textiles, air filter, tooth paste), incorporated with nanoparticles for their manufacturing (Federici et al. 2007 \& Dawson et al. 2008 ). So, focusing on environmental safety and to reduce toxicity of metals nanoparticles, eco-friendly 
International Journal of Trend in Scientific Research and Development (IJTSRD) ISSN: 2456-6470

nanoparticles had been synthesized using various biological sources. Some of the seaweeds had been reported for its mediated nanoparticles synthesis and had been reported for their various medical applications especially antibacterial activity (Shanmugam et al. 2014; Venkatpurwar and Pokharkar, 2011); and water filters (Jain and Pradeep, 2005), bio sensors (Chen et al. 2007), in controlling plant pathogens (Krishnaraj et al. 2012) and antifungal activity (Devi et al. 2014; Kumar et al. 2013). Recently, seaweeds liquid bio-fertilizer has been reported for promoting the growth of various cereals crops and vegetables (Hernández-Herrera et al. 2013; Safinaz et al. 2013; \& Soad et al. 2016). In this present work, the seaweed synthesized extracellular eco-friendly silver nanoparticles have been evaluated for its photo-toxicity for studying their effect on seed germination including the analysis of its biochemical compositions, total phenol and in-vitro- antioxidant activities. The aim of this study is to analyse the properties of seaweeds mediated silver nanoparticles as nano bio-fertilizer.

\section{MATERIALS AND METHODS:}

\section{Synthesis of Silver Nanoparticles:}

Seaweed extract preparation: The fresh seaweed had been collected from Vadakkadu $\left(09^{\circ} 19.700 \mathrm{~N} \&\right.$ $\left.079^{\circ} 19.072 \mathrm{E}\right)$, Rameshwaram, south-east coast of India. Seaweed was identified with standard taxonomic key of CMFRI. It was washed with in-situ sea water and distilled water thrice. Then, $20 \mathrm{gm}$ of seaweed was cut into very small pieces and grinded to make it powder and was dissolved into $100 \mathrm{ml}$ of distilled water and boiled for 10 minutes. The crude extract of seaweed was filtered with Whatman No. 1 filter paper and repeatedly filtered with thin layer of cotton to get clear seaweed extract. This crude seaweed extract was stored in $4^{\circ} \mathrm{C}$ for further use.

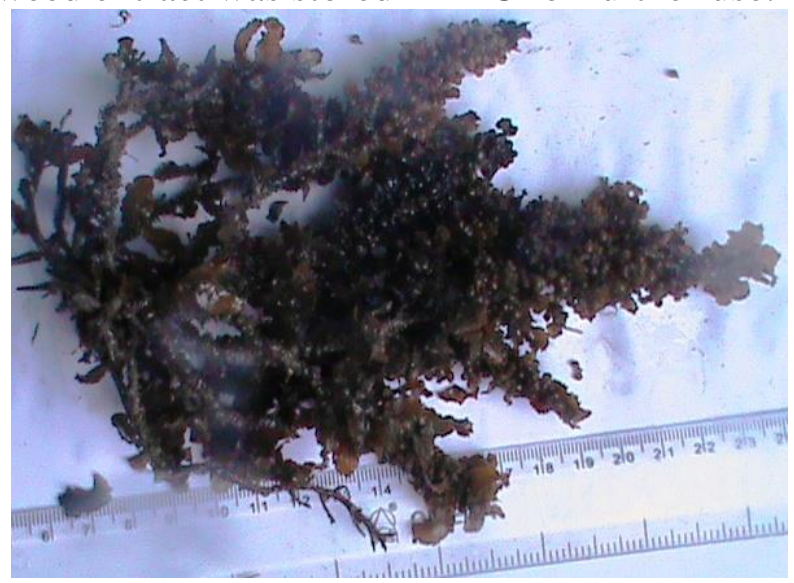

Fig 1: Sargassum cinctum
Synthesis of Ag-Nanoparticles: The aqueous $1 \mathrm{mM}$ $\mathrm{AgNO}_{3}$ solution was prepared with Silver nitrate. For typical synthesis of Silver nanoparticles, $10 \mathrm{ml}$ of the aqueous extract of seaweed was added to the $90 \mathrm{ml}$ aqueous solution of Silver Nitrate in $250 \mathrm{ml}$ conical flask and kept in room temperature for 72 hours within mechanical shaker at $120 \mathrm{rmp}$. The colour change of solution indicated the formation of silver nanoparticles.

\section{Characterization of Ag-Nanoparticles:}

UV-Vis Spectrophotometer: After 72 hours synthesis of particles, for characterization, the solution was scanned (300-700nm) with UV-Vis Spectrophotometer (UV-2600 SHIMADZU) and distilled water was used as blank.

\section{Fourier Transform Infrared (FT-IR) Spectroscopy:}

After synthesis of particles, the solution had been centrifuged at $5000 \mathrm{rmp}$ for 30 minutes to precipitate the pellet of particles at the bottom, then the supernatant were removed and pellet collect and dried at room temperature to make dry powder. The chemical composition of the seaweed was characterized by Perkin Elmer FTIR model 2000. The $1 \mathrm{mg}$ of dry powder of particles was mixed with $\mathrm{KBr}$ and made it pellet and used for FT-IR analysis at $\mathrm{KBr}$ mode.

\section{Scanning Electron Microscopy:}

The dry powder of sample was analysed using JEOL JSM-5610LV Scanning Electron Microscope. Thin films of the sample was prepared on a gold coated copper grid by just spraying a very small amount of the powder sample on the grid; and then the film on the SEM grid was allowed for observation.

Estimation biochemical compositions: The crude carbohydrate was estimated by the standard Anthrone method (Hedge et al. 1962); crude proteins by biuret method (Goshev et al. 1979) and crude lipid estimated by (Yang et al. 2014).

Estimation of total phenolic content (Folin Ciocalteu's method): The $500 \mathrm{mg}$ seaweed powder was dissolved in ethanol, methanol and acetone and kept for 24 hours and after 15 minutes centrifugation at $5000 \mathrm{rmp}$, the supernatant was collected for determination of total phenols. The $1 \mathrm{ml}$ of aliquots of ethanol, methanol and acetone extracts and standard 
International Journal of Trend in Scientific Research and Development (IJTSRD) ISSN: 2456-6470

gallic acid $(10,20,40,60,80,100 \mu \mathrm{g} / \mathrm{ml})$ were positioned into the test tubes and $5 \mathrm{ml}$ of distilled water and $0.5 \mathrm{ml}$ of Folin Ciocalteu's reagent were mixed and shaken. After 5 minutes, $1.5 \mathrm{ml}$ of $20 \%$ sodium carbonate was added and volume made up to10 $\mathrm{ml}$ with distilled water. It was allowed to incubate for 2 hours at room temperature. Intense blue color was developed. After incubation, absorbance was measured at $750 \mathrm{~nm}$ spectrophotometer using Perkin Flmer precisely Lambda 25 UV/Vis Spectrophotometer. The extracts were performed in triplicates. The blank was performed using reagent blank with solvent. Gallic acid was used as standard. The calibration curve was plotted using standard gallic acid. The data for total phenolic contents of seaweed was expressed as $\mathrm{mg}$ of gallic acid equivalent weight (GAE)/ $100 \mathrm{~g}$ of dry mass (Bhalodia et al., 2011; Patel et al., 2010).

\section{Estimation of total antioxidant activity} (Phosphomolybdate assay): Total antioxidant activities of methanol, ethanol and acetone extracts were obtained by phospho-molybdate method using ascorbic acid as a standard (Lallianrawna et al. 2013). Briefly, the $7.45 \mathrm{ml}$ of $\mathrm{H}_{2} \mathrm{So}_{4}(0.6 \mathrm{mM}$ solution), sodium sulphate of $0.9942 \mathrm{~g}(28 \mathrm{mM})$ in addition to $1.2359 \mathrm{gm}$ ammonium molybdate $(4 \mathrm{mM})$ mixed in $250 \mathrm{ml}$ distilled water to prepare the TAC reagent. The $300 \mu \mathrm{l}$ of seaweed extracts were mixed with $3 \mathrm{ml}$ of TAC reagent. The reaction mixtures were incubated at $95^{\circ} \mathrm{C}$ for 90 minutes under water bath. Absorbance of all the sample mixtures was measured at $695 \mathrm{~nm}$ against a blank on a UV-visible spectrophotometer. Total antioxidant activity was expressed as the number of equivalents of ascorbic acid in milligram per gram of extract. A typical blank contained $1 \mathrm{ml}$ of the reagent solution along with an appropriate volume of the solvent and incubated under similar conditions. The antioxidant capacity of plant extract solution was estimated using following formula: Total antioxidant capacity, TAC (\%): = $[($ Control absorbance - Sample absorbance) / (Control absorbance)] x 100

(iii) Free Radical (DPPH-2,2-diphenyl-1picrylhydrazyl) Scavenging Activity: The scavenging activity of methanol, ethanol and acetone extracts of seaweed were determined according to standard protocol (Surana et al. 2016). Briefly, $2.0 \mathrm{ml}$ of $0.16 \mathrm{mM}$ DPPH solution in methanol was added to the test tube containing $2.0 \mathrm{ml}$ aliquot of sample. The mixture was vortexed for 1 minute and kept at room temperature for 30 minutes in the dark. The absorbance of all the sample solutions was measured at $517 \mathrm{~nm}$. Sampleblank and Control sample were performed according to the method. Scavenging activity of DPPH radical was calculated using the following equation

Percentage inhibition $=\left(\underline{A}_{\text {control }}-A_{\text {sample }}\right) \times 100$ $\mathrm{A}_{\text {control }}$

Where $A_{\text {sample }}$ is the Absorbance of DPPH solution with sample, $A_{\text {control }}$ is the blank absorbance. Synthetic antioxidant Ascorbic acid was used as positive control.

\section{Seed germination test (Raquel Barrena et al., 2009):}

The seeds of Abelmoschus esculentus (FamilyMalvaceae) were dipped within 5\% Sodium hypochlorite solution for 15 minutes to ensure seed surface sterility and soaked with Silver Nanoparticles solution for overnight and seeds were also soaked for overnight with normal tape water as control. Then, each piece of filter paper was wetted with $5 \mathrm{ml}$ Silver nanoparticles solution and placed in the Petri plates. The treated seeds were kept on filter paper within Petri plates. Then Petri plates were covered and incubated at room temperature. After 12 hours germination halted and the germination percentage, mean germination time, germination index, relative root elongation, relative seed germination and germination rate were estimated. Germination parameters were calculated using the following equations (Singaravelu et al. 2007; Taga et al. 1984 and Thakkar et al. 2010).

Germination Percentage $(\mathrm{GP} \%)=(\mathrm{Gf} / \mathrm{n}) \times 100$

Where Gf is the total number of germinated seeds at the end of experiment and $n$ is the total number of seed used in the test.

Mean Germination Time $(\mathrm{MGT})=\Sigma \mathrm{NiDi} / \mathrm{n}$

where $\mathrm{Ni}$ is number of germinated seeds until the $\mathrm{i}^{\text {th }}$ day and Di is number of days from the start of experiment until the ith counting and $\mathrm{n}$ is the total number of germinated seeds.

Germination Rate $(\mathrm{GR})=\Sigma \mathrm{Ni} / \Sigma \mathrm{Ti} \mathrm{Ni}$

where $\mathrm{Ni}$ is the number of newly germinated seeds at time Ti. 
$\mathrm{GR}=(\mathrm{a} / 1)+(\mathrm{b}-\mathrm{a} / 2)+(\mathrm{c}-\mathrm{b} / 3)+\ldots . .+(\mathrm{n}-\mathrm{n}-1 / \mathrm{N})$

Relative root elongation (E)

$=($ Mean root length with NPs) / (Mean root length with control) $\times 100$

Germination index (GI)

$=($ Relative seed germination $) \times($ Relative root elongation) / 100

Where,

Relative seed germination

$=($ Seeds germinated with NPs) / (Seeds germinated with control) $\times 100$

\section{Statistical Analysis}

Mean and standard deviations were derived from measurements on three replicates for each treatment and the related controls for biochemical composition and total phenol.

\section{RESULTS \& DISCUSSIONS:}

Synthesis of Silver Nanoparticles: It is well known that Ag-NPs exhibit reddish-brown in water (Damle et al. 2002). The mixing of seaweed aqueous solution with Silver Nitrate $(1 \mathrm{mM})$ produced dark brownish colour in compare to control Silver nitrate solution and the aqueous seaweed solution which suggested the formation of Ag-NPs by reduction of the aqueous $\mathrm{Ag}+$ (fig 2). Due to the surface Plasmon vibrations among the produced silver nanoparticles, the color change occurred (Mulvaney et al. 1996)

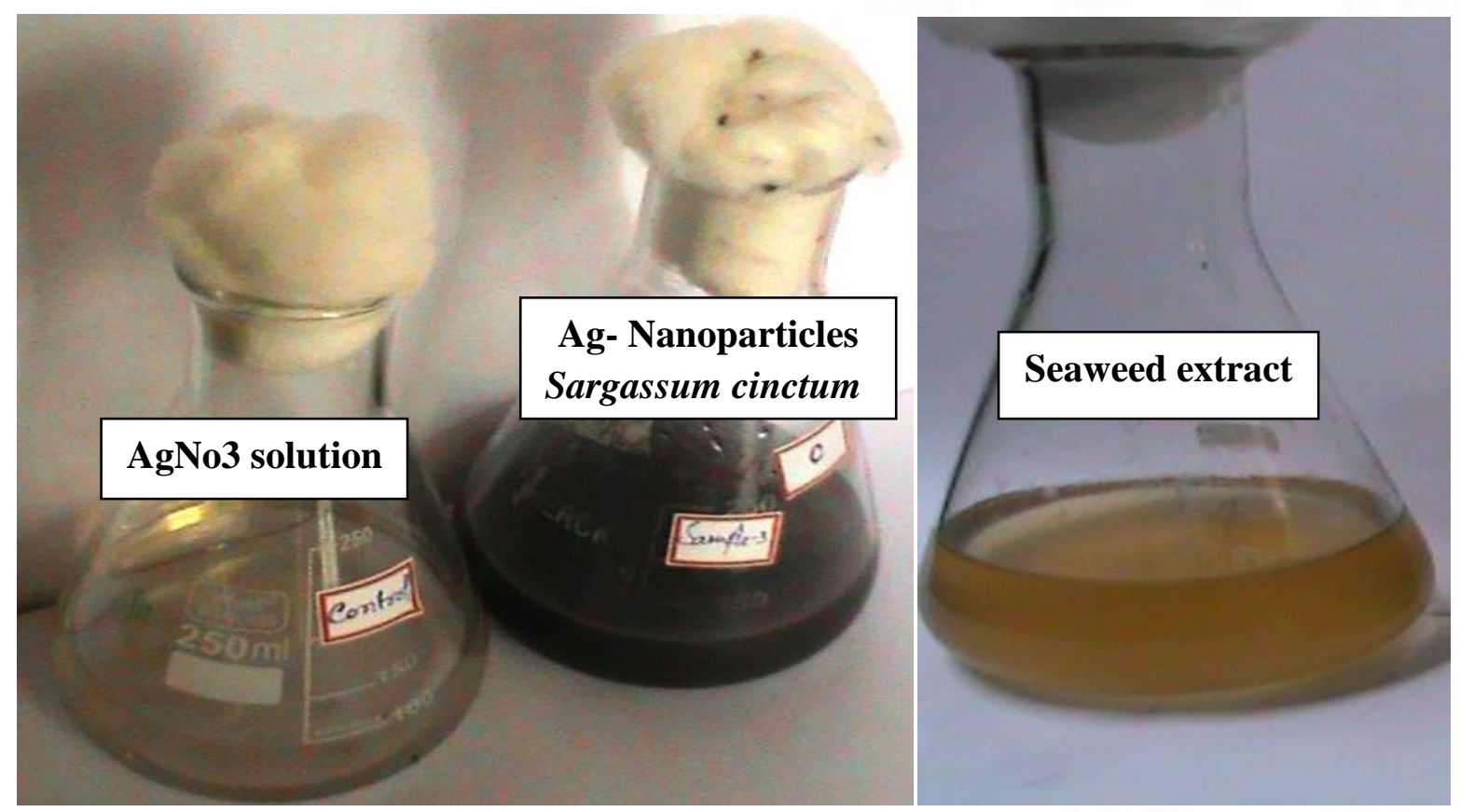

Figure 2: Showing the synthesis of nanoparticles 


\section{Characterization of synthesized nanoparticles:}

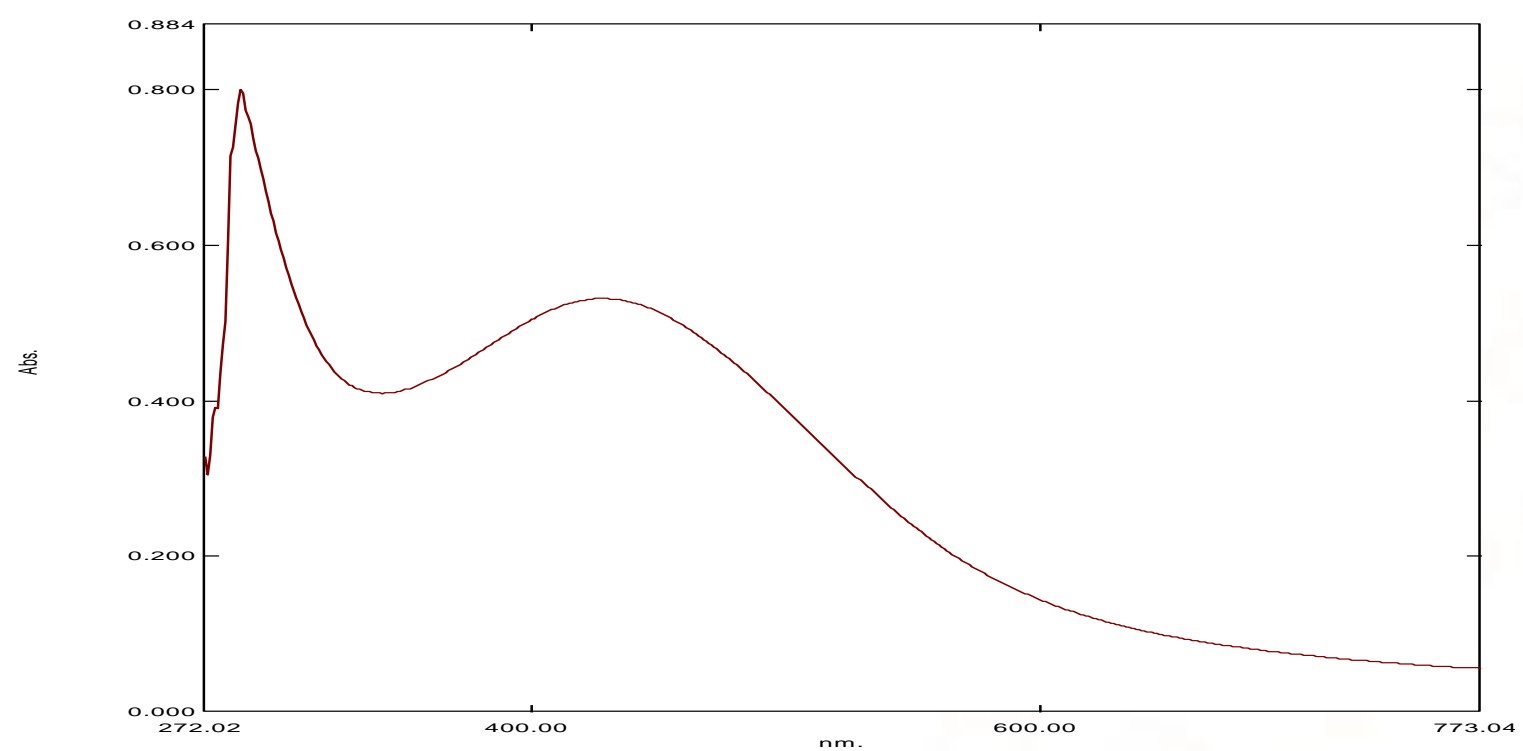

Figure 3: UV-Vis Spectra of Sargassum cinctum 420nm - 0.563

$425 \mathrm{~nm}-0.565$

$430 \mathrm{~nm}-0.565$

$435 \mathrm{~nm}-0.564$

UV-Visible Spectroscopic absorbance peak at 425 to $430 \mathrm{~nm}$ for Sargassum cinctum indicated the synthesis of silver nanoparticles.

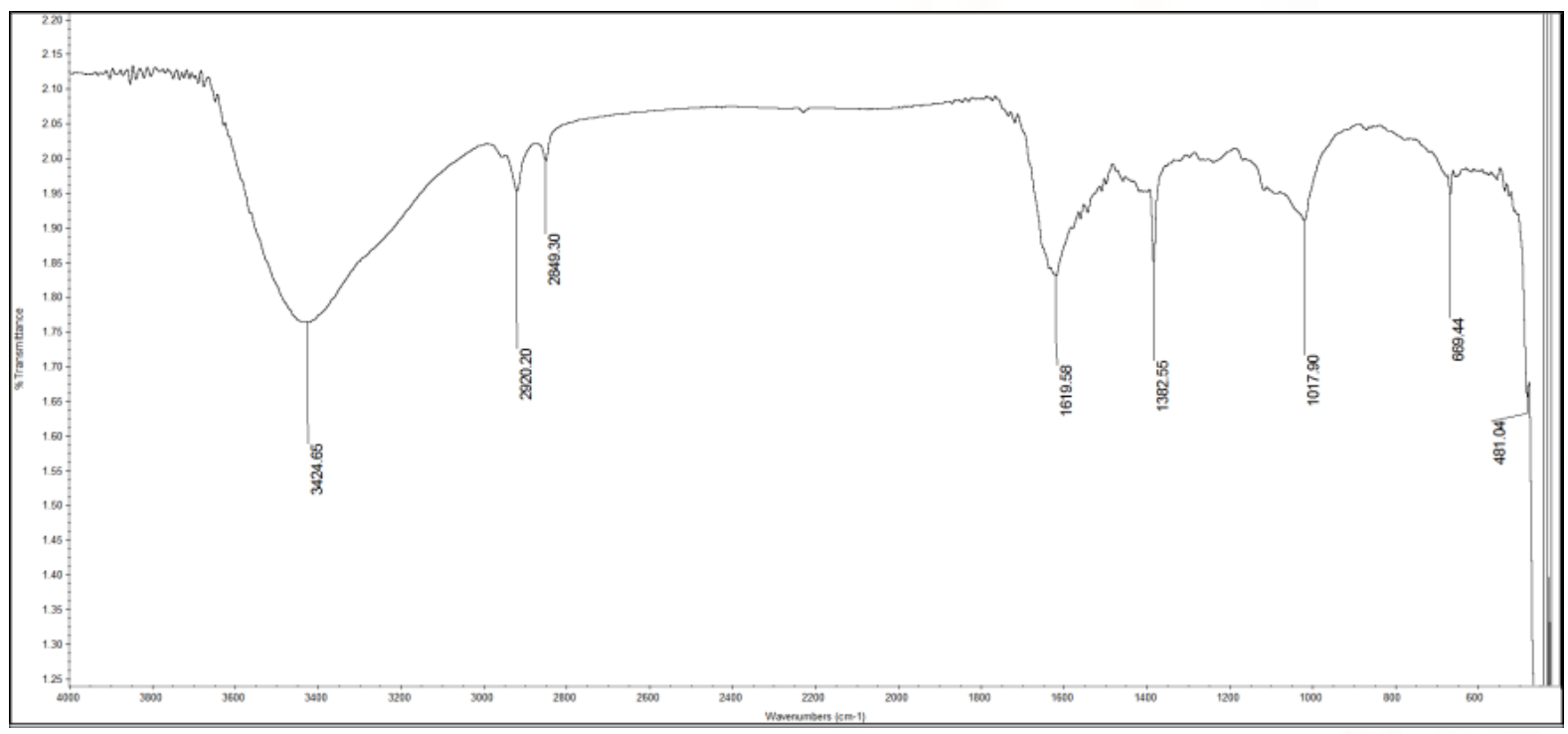

Fig 4: FT-IR spectra of silver nanoparticles synthesized by Sargassum cinctum extract.

The seaweed mediated silver nanoparticles were analysed for the characterization of their functional groups and their properties (table 1). 
International Journal of Trend in Scientific Research and Development (IJTSRD) ISSN: 2456-6470

Table 1: FT-IR peak values of Sargassum cinctum mediated silver nanoparticles

\begin{tabular}{|l|l|l|}
\hline Peaks & Bonds & Functional Groups \\
\hline $\mathbf{6 6 9 . 4 4}$ & C-Cl, C-Br Stretch & Alkyl halide \\
\hline $\mathbf{1 0 1 7 . 9 0}$ & C-F Bend & Alkyl halide \\
\hline $\mathbf{1 3 8 2 . 5 5}$ & C-H Stretch, C-N bend & Alkane, Amine \\
\hline $\mathbf{1 6 1 9 . 5 8}$ & C=C Bending & Aromatic \\
\hline $\mathbf{2 8 4 9 . 3 0}$ & C-H Stretch & Alkyl \\
\hline $\mathbf{2 9 2 0 . 2 0}$ & O-H Stretch & Carboxylic compounds \\
\hline $\mathbf{3 4 2 4 . 6 5}$ & N-H Stretch & $1^{\circ}, 2^{\circ}$ Amines, Amides \\
\hline
\end{tabular}

The results revealed from table 1 showed that the capping of ligand of the Ag-NPs may be an alkyl halide, alkanes, aromatic compound or carboxylic compound, or amide and amines

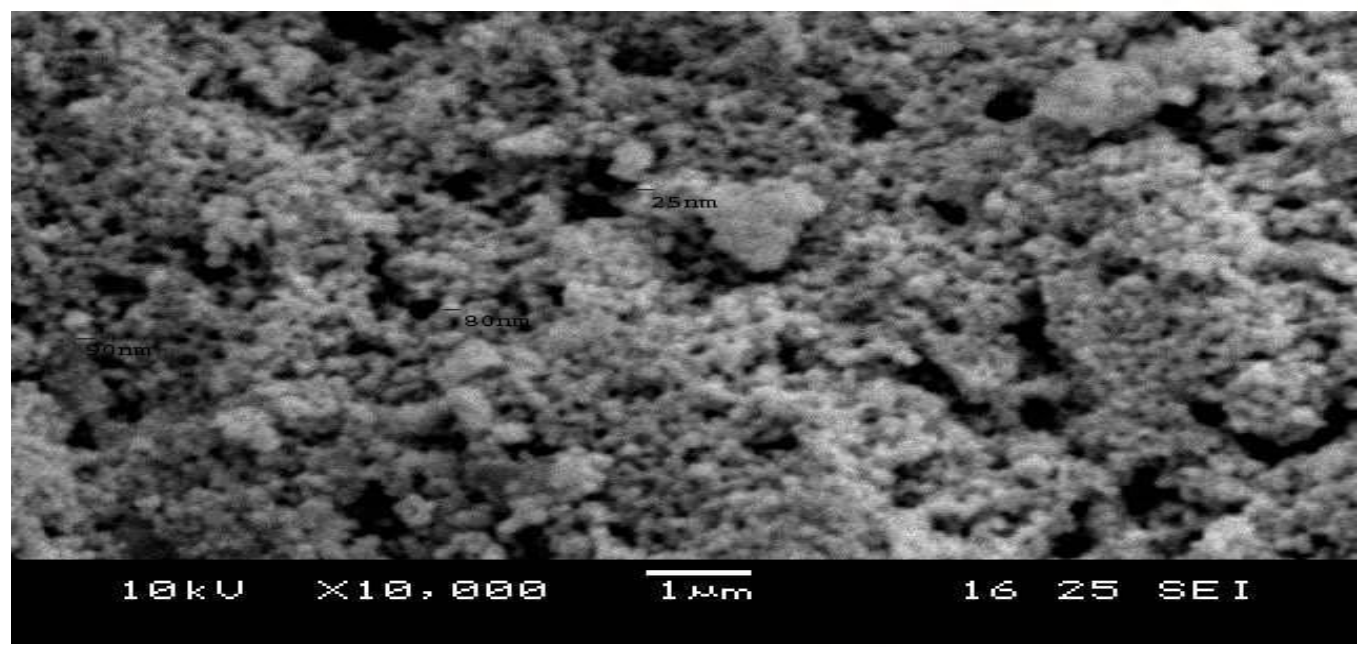

Fig 5. SEM micrograph of silver nanoparticles synthesised by the reaction of $1 \mathrm{mM}$ silver nitrate with Sargassum cinctum extract.

The SEM image (Fig 5) showing the high density, spherical shaped and well distributed Ag-NPs synthesized from Sargassum cinctum extract.

\section{Preliminary Biochemical components, antioxidant and total phenol analysis:}

The protein content of Sargassum cinctum is comparatively high than carbohydrates and lipid. The protein, carbohydrates and lipid content of this species was $87.17 \pm 0.66 \mathrm{mg} / \mathrm{g}$ dry wt.; $38.49 \pm 0.54 \mathrm{mg} / \mathrm{g}$ dry wt.; and $28.7 \pm 0.6 \mathrm{mg} / \mathrm{g}$ dry wt. but starch content is very low, $0.1 \pm 0.00 \mathrm{mg} / \mathrm{g}$ dry wt. (Fig 6)
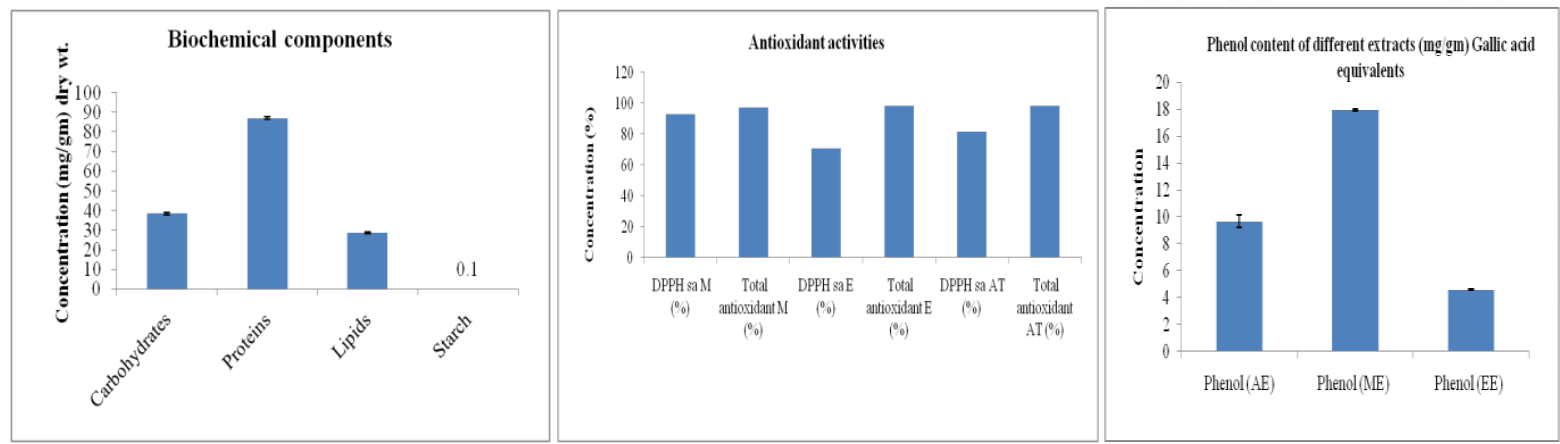

Fig 6: Graph representing the values of biochemical components;

Fig 7: Seaweed extracts anti-oxidant activity;

Fig 8: Seaweed extracts total phenol content 
Three different extracts such as methanol, ethanol and acetone of seaweeds were used for the estimation of in-vitro anti-oxidant activities such as total antioxidant activity and free radical (DPPH) scavenging activity which revealed that methanol extract had the highest free radical (DPPH) scavenging activity $(92.36 \%)$ in compare to ethanol (70.68\%) and acetone $(81.17 \%)$ extract, But the total antioxidant activity of three extracts were more or less equal (methanol extract-96.67\%; ethanol-98.05\% and acetone-98 \%). It had been concluded that Sargassum cinctum three extracts had high antioxidant activities (Fig 7).

The total phenol content of methanol extracts $(17.93 \pm$ $0.66 \mathrm{mg} / \mathrm{gm}$ ) gallic acid equivalents of Sargassum cinctum was the highest in compare to ethanol extract $(9.65 \pm 0.46 \mathrm{mg} / \mathrm{gm})$ gallic acid equivalents and acetone extract $(4.6 \pm 0.06 \mathrm{mg} / \mathrm{gm})$ gallic acid equivalents (Fig 8).

\section{Seed Germination test :}

The main objective of this work is to evaluate the effect of silver nanoparticles synthesized from Sargassum cinctum on phyto-toxicity by testing its effect on seed germination and seedling growth. After synthesis, the Ag- nanoparticles solution of seaweed was directly used for test to seed germination and the Ag-nanoparticles solution was also directly used for test to seedling growth of Abelmoschus esculentus. The above mentioned formula were used for the determination of germination percentage which showed that seaweed mediated Ag- nanoparticles had better germination percentage $(80 \%)$ than water $(40 \%)$. The seed germination parameters were measured after 24 hours, 48 hours and 96 hours. After 24 hours germination percentage was $60 \%$ and after 48 and 96 hours $80 \%$ for seaweed $\mathrm{Ag}$ - nanoparticles solution but in case of control it was $40 \%$ after 24,48 and 96 hours. Mean germination time increased with increase of time and it was maximum at 96 hours. The germination rate was the highest after 24 hours and gradually decreasing at 48 hours and 96 hours. Germination index was calculated with relative root elongation and relative seed germination and it had been observed that germination index was the highest at 48 hours (368.88) in compare to 24 hours and 96 hours.

It had been previously reported that metallic Agnanoparticles had dose dependent inhibitory effect on seed germination. The inhibitory effect of metallic Ag- Nanoparticles had been influenced by various factors such as size and concentration of nanoparticles, temperature, duration and methods of exposure. The dosage of 0.2 to $1.6 \mathrm{mg} / \mathrm{L}$ of $\mathrm{Ag}-\mathrm{NPs}$ had been shown to inhibit seed germination, lipase activity and soluble reducing sugar content in Brassica nigra (Amooaghaiea et al. 2015). The 10 $\mathrm{mg} / \mathrm{ml} \mathrm{Ag} \mathrm{NPs} \mathrm{had} \mathrm{been} \mathrm{reported} \mathrm{to} \mathrm{inhibit} \mathrm{the} \mathrm{seed}$ germination in Hordeum vulgare and reduced shoot length in flax (Linum usitatissimum) and barley (Hordeum vulgare) (Nowack, 2010; Kaegi et al. (2010); El-Tesah et al. 2012). Some of the studies had been reported that metallic AgNPs had no significant effect on Cucumis sativus or Lactuca sativa (Barrena et al. 2009). From our study, it had been reported that seaweed mediated eco-friendly Silver nanoparticles had positive effect and it is phyto-friendly and promoting growth of seedlings and positively effected on seed germination. In compare to normal water, green synthesized silver nanoparticles had better effect on seed germination which may be due to presence of adequate amount of minerals and antioxidant and the biochemical component in seaweed extract which is used for synthesis of $\mathrm{Ag}$ nanoparticles.

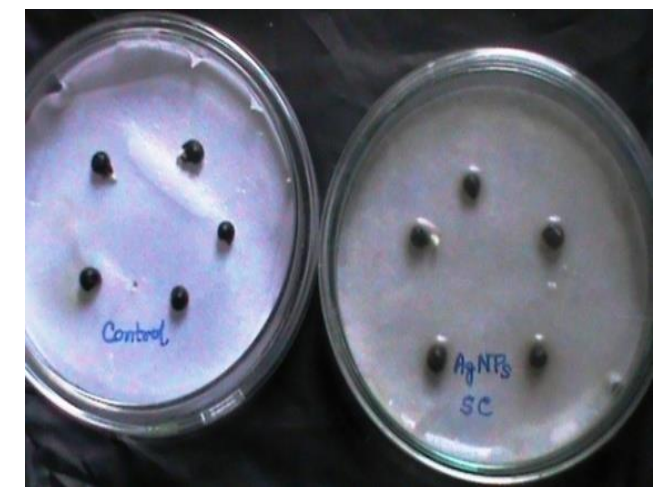

Fig 9 (a): Seed germination with normal water and seaweed Ag-nanoparticles

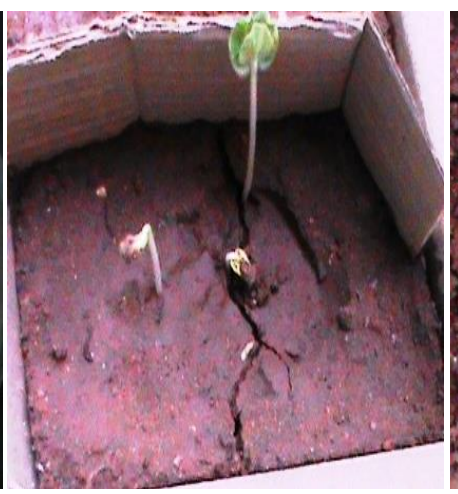

Fig 9 (b): Seedling with normal water as control

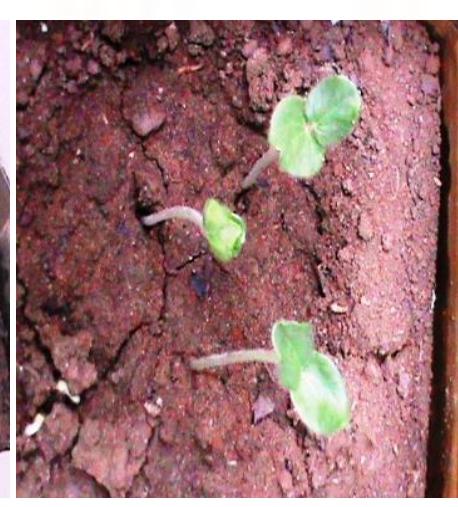

Fig 9 (c): Seedlings with seaweed synthesized Ag- Nanoparticles 


\begin{tabular}{|c|c|c|c|c|}
\hline \multicolumn{5}{|c|}{ Table 2 : Seedling height (cm) after 6 days } \\
\hline Sample Id & 1 & 2 & 3 & Mean \\
\hline Control ( tape water) & 12 & 7.5 & 6.7 & 8.73 \\
\hline Sargassum cinctum Ag-NPs & 11.2 & 11.5 & 12.3 & 11.66 \\
\hline
\end{tabular}

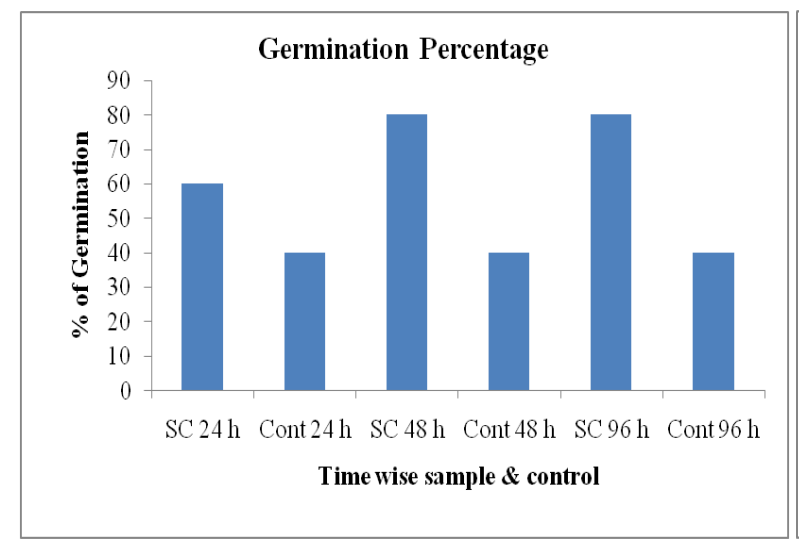

Fig 10 (a) seed germination percentage

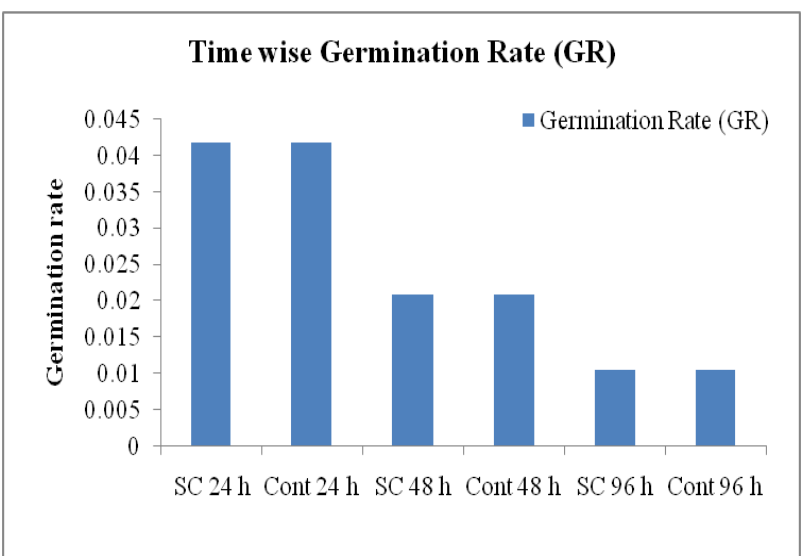

Fig 10 (c) Germination rate

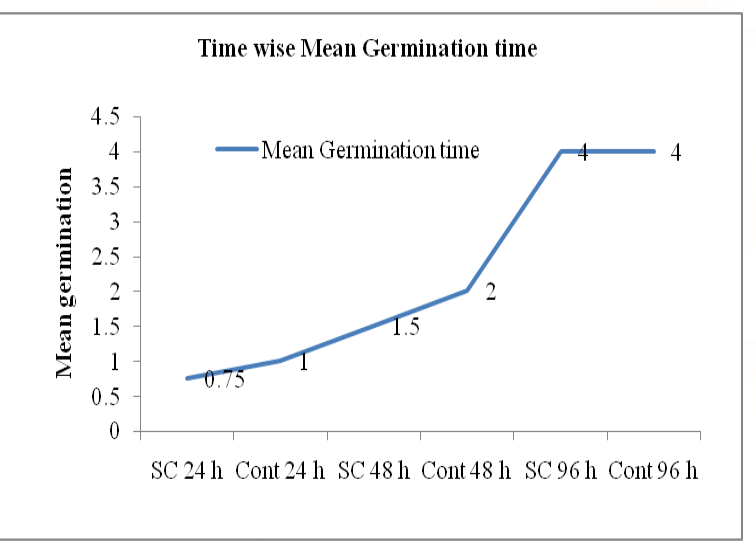

Fig 10 (b) Mean germination time

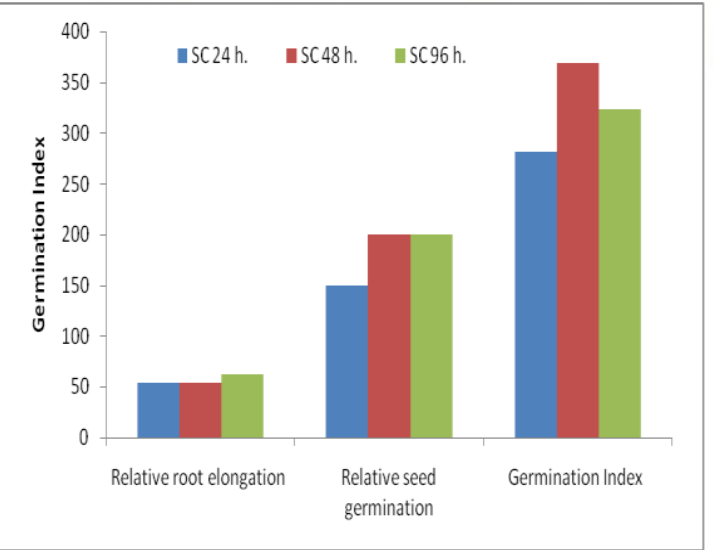

Fig 10 (d) Germination index

\section{Acknowledgements:}

Authors are like to thank Dr. A. Saravana Kumar and his student to give the facilities to use spectrophotometer. The authors are thankful to Dr. B. Shanthi and Dr. K. Siva Kumar at the Centralised Instrumentation and Service laboratory (CISL) at Department of Physics, Annamalai University for providing the Scanning Electron Microscopy and students of Dr. S. Kabilan, at Department of Physics for providing the FT-IR facility. Our sincere thanks to the Dean, Faculty of Marine Sciences, and Director, Centre of Advanced Study in Marine Biology, Faculty of Marine Sciences, Annamalai University for proving the facilities to carry out this work successfully. Authors are also thankful to higher authorities of Annamalai University.

Conflict of interest: There is no conflict of interest to be declared.

\section{REFERENCES:}

1. Amooaghaiea, R., Tabatabaeia, F., Ahadia, A.-M, (2015). Role of haematin and sodium nitroprusside in regulating Brassica nigra seed germination under Nanosilver and silver nitrate stresses, Ecotox. Environ. Safe., Vol. 113, pp. 259-270.

2. Barrena, R., Casals, E., Colon, J. Font, X. Sanchez, A. Puntes, V. (2009). Evaluation of the eco-toxicity of model nanoparticles", Chemosphere, vol. 75, pp. 850-857.

3. Bhalodia, N. R., Nariya, P. B., Acharya, R. N., Shukla, V. J., 2011, Evaluation of in vitro antioxidant activity of flowers of Cassia fistula Linn. International Journal of Pharm. Tech Research. IJPRIF ISSN: 0974-4304, Vol. 3, No.1, pp 589-599. 
International Journal of Trend in Scientific Research and Development (IJTSRD) ISSN: 2456-6470

4. Chakraborty, S., \& Santra, S.C., (2008). Biochemical composition of eight benthic algae collected from Sundarban. Indian J Mar Sci 37:329-332

5. Chen, H., Hao, F., He. R., Cui, DX., (2007) Chemiluminescence of luminol catalyzed by silver nanoparticles. J Colloids Interface Sci315:158163

6. Damle, C., Kumar, A., and Sastry, M. (2002), Synthesis of $\mathrm{Ag} / \mathrm{Pd}$ nanoparticles and their lowtemperature alloying within thermally evaporated fatty acid films. J. Phys. Chem. B, 106, 297-302

7. Dawson, N.G. (2008). Sweating the small stuff: environmental risk and nanotechnology. Bioscience.58(8):690.

8. Devi, J. S., and Bhimba, B. V. (2014). Antibacterial and antifungal activity of Silver nanoparticles synthesized using Hypnea musciformis. Biosciences Biotechnology Research Asia, Vol. 11(1), 235-238

9. Elechiguerra, J. L., Burt, J. L., Morones, J. R., Bragado, A. C., Gao, X., Lara, H. H., Yocaman, M., (2005) Interaction of silver nanoparticles with HIV-1. J Nanobiotechnol 3:6

10. El-Temsah, Y. S. Joner, E. J. (2012). Impact of $\mathrm{Fe}$ and $\mathrm{Ag}$ nanoparticles on seed germination and differences in bioavailability during exposure in aqueous suspension and soil, Environ. Toxicol. Vol. 27, pp. 42-49,

11. Farré, M, Gajda-Schrantz, K, Kantian,i L, Barceló, D.(2009). Ecotoxicity and analysis of nanomaterials in the aquatic environment. Anal Bioanal. Chem.; 393(1):81-95.

12. Federici, G., Shaw, B.J, and Handy, R. D. Toxicity of titanium dioxide nanoparticles to rainbow trout (Oncorhynchus mykiss): gill injury, oxidative stress, and other physiological effects. Aquat Toxicol. 2007; 84(4):415-30.

13. Goshev, I. and Nedkov, P. (1979). Extending the range of application of the biuret reaction: Quantitative determination of insoluble proteins. Anol. Lliuchrm. 95:340-343.

14. Hedge, J. E. and Hofreiter, B. T. (1962). In: Carbohydrate Chemistry, 17 (E ds. Whistler R. and Be Miller, J.N.,) Academic Press, New York.

15. Hernández-Herrera, R. M., Santacruz-Ruvalcaba, F., Ruiz-Lopez, M. A., Norrie, J., \& HernándezCarmona, G., (2013) Effect of liquid seaweed extracts on growth of tomato seedlings (Solanum lycopersicum L.). J. Appl. Phycol. DOI 10.1007/s10811-013-0078-4
16. Jain, P., Pradeep, T., (2005) Potential of silver nanoparticles-coated polyurethane foam as an antibacterial water filter. Biotechnol. Bioeng, 90:59-63

17. K. N. Thakkar, S. S. Mhatre and R. Y. Parikh, (2010). Biological synthesis of metallic nanoparticles. Nanomedicine, 6(2): 257-262.

18. Kaegi, R. Sinnet, B. Zuleeg, S. Hagendorfer, H. Mueller, E. Vonbank, (R. 2010). Release of silver nanoparticles from outdoor facades, Environ. Pollut. vol. 158, no. 9, pp. 2900-2905,

19. Klaine, S.J, Alvarez, P.J, Batley, G.E, Fernandes, T.F, Handy, R.D, Lyon, D.Y., (2008).Nanomaterials in the environment: behaviour, fate, bioavailability, and effects. Environ Toxicol Chem. 27(9):1825-51.

20. Krishnaraj, C., Jagan, E.G., Ramachandran, R., Abirami, S.M., Mohan N, Kalaichelvan, P.T., (2012) Effect of biologically synthesized silver nanoparticles on Bacopa monnieri (Linn.) Wettst. plant growth metabolism. Process Biochem 47:651-658

21. Kumar, P., Selvi, S. S., Govindaraju, M., (2013). Seaweed-mediated biosynthesis of silver nanoparticles using Gracilaria corticata for its antifungal activity against Candida spp. Appl. Nanosci; 3:495-500; DOI 10.1007/s13204-0120151-3

22. Lallianrawna, S., Muthukumaran, R., Ralte, V., Gurusubramanian, G., Kumar, S., 2013. Determination of total phenolic content, total flavonoids content and total antioxidant capacity of Ageratina adenophora (Spreng.) King \& H., Rob Sci Vis Vol. 13 Issue No. 4 ,

23. Manivannan, K., Devi, G.K., Thirumaran, G., Anantharaman, P. (2008b). Mineral composition of marine macroalgae from Mandapam Coastal regions; Southeast Coast of India. Am-Euras J Bot 1:58-67

24. Manivannan, K., Thirumaran, G., Devi, GK., Anantharaman, P., Balasubramanian, T. (2009). Proximate composition of different group of seaweeds from Vedalai Coastal waters (Gulf of Mannar): Southeast Coast of India. Middle-East J Sci Res 4:72-77

25. Manivannan, K., Thirumaran, G., Devi, GK., Hemalatha, A., Anantharaman, P. (2008a). Biochemical composition of seaweeds from Mandapam Coastal regions along Southeast Coast of India. Am-Euras. J Bot 1:32-37 
International Journal of Trend in Scientific Research and Development (IJTSRD) ISSN: 2456-6470

26. Marsham, S., Scott, G.W., Tobin, M.L., (2007). Comparison of nutritive chemistry of a range of temperate seaweeds. Food Chem.100:1331-1336

27. Matanjun, P., Mohamed, S., Mustapha, N.M., Muhammad, K., (2009). Nutrient content of tropical edible seaweeds, Eucheuma cottonii, Caulerpa lentillifera and Sargassum polycystum. J Appl. Phycol. 21:75-80

28. McDermid, K.J., Stuercke, B., (2003) Nutritional composition of edible Hawaiian seaweeds. J Appl. Phycol 15:513-524

29. Mulvaney, P., (1996) Surface Plasmon Spectroscopy of Nanosized Metal Particles. Langmuir, , 12 (3), pp 788-800 ; DOI: $10.1021 / 1 a 9502711$

30. Nowack, B. (2010). Nanosilver revisited downstream, Science, vol. 330, pp. 1054-1055,

31. Ortiz, J., Romero, N., Robert, P., Araya, J., LopezHernández, J., Bozzo, C., Navarrete, E., Osorio, A., Rios, A., (2006). Dietary fiber, amino acid, fatty acid and tocopherol contents of the edible seaweeds Ulva lactuca and Durvillaea antarctica. Food Chem 99:98-104

32. Patel, V. R., Patel, P. R., Kajal, S. S., 2010, Antioxidant activity of some selected medicinal plants in Western Region of India, Advances in Biological Research 4 (1): 23-26.

33. R. Barrena, E. Casals, J. Colon, X. Font, A. Sanchez and V. Puntes, (2009). Evaluation of the ecotoxicity of model nanoparticles. Chemosphere, 75 (7) : 850-857.

34. Roy, S., \& Anantharaman, P., Heavy Metals Accumulation of Different Parts of Turbinaria spp. along the Olaikuda Coast, Rameshwaram, Tamilnadu, India. International Advanced Research Journal in Science, Engineering and Technology ISO 3297:2017 Certified Vol. 4, Issue 3, March 2017 b

35. Roy, S., \& Anantharaman, P., Minerals Composition of Marine Macro Algae Collected from Olaikuda, Rameshwaram, Gulf of Mannar, Southeast Coast of India. International Advanced Research Journal in Science, Engineering and Technology ISO 3297: 2007 Certified Vol. 4, Issue 6, a

36. Rupérez, P., (2002) Mineral content of edible marine seaweeds. Food Chem. 79:23-26.

37. Safinaz, A. F. and Ragaa, A. H. (2013). Effect of some red marine algae as bio-fertilizers on growth of maize (Zea mayz L.) plants. International Food Research Journal 20(4): 1629-1632
38. Shanmugam, N. Rajkamal, P., Cholan, S., Kannadasan, N., Sathishkumar, K., Viruthagiri , G., \& Sundaramanickam, A. Biosynthesis of silver nanoparticles from the marine seaweed Sargassum wightii and their antibacterial activity against some human pathogens. Appl Nanosci. (2014) 4: 881-888

39. Singaravelu, G.,Arockiyamari, J.Ganesh Kumar, V. And Govindaraju, K. (2007). A novel extracellular biosynthesis of monodisperse gold nanoparticles using marine algae, Sargassum wightii Greville. Colloids and Surfaces B: Biointerfaces, 57(1): 97-100.

40. Soad, M, and El-Din, M. (2016). Utilization of seaweed extracts as bio-fertilizers to stimulate the growth of wheat seedlings. Egypt. J. Exp. Biol. (Bot.), 11(1): $31-39$.

41. Surana, A. R., Kumbhare, M. R., Wagh, R. D., 2016. Estimation of total phenolic and total flavonoids content and assessment of in vitro antioxidant activity of extracts of Hamelia patens Jacq. Stems. Research Journal of PhytochemistryISSN1819-3471, 10(2): 67-74.

42. Taga, M. S. Miller, E. E. D. E. and Pratt, (1984). Chia seeds as a source of natural lipids antioxidants. J Am Oil Chem Soc. 61(5): 928-993.

43. Venkatpurwar, V., Pokharkar, V., (2011) Green synthesis of silver nanoparticles using marine polysaccharide: study of in vitroantibacterial activity. Mater Lett 65:999-1002

44. Williams, D., (2008) The relationship between biomaterials and nanotechnology. Biomaterials 29:1737

45. Yang, F., Xiang, W., Sun, X., Wu, H., Li, T., and Long, L., (2014). A novel lipid extraction method from wet microalga Picochlorum sp. at room temperature. Marine drugs. ISSN 1660-3397. 